
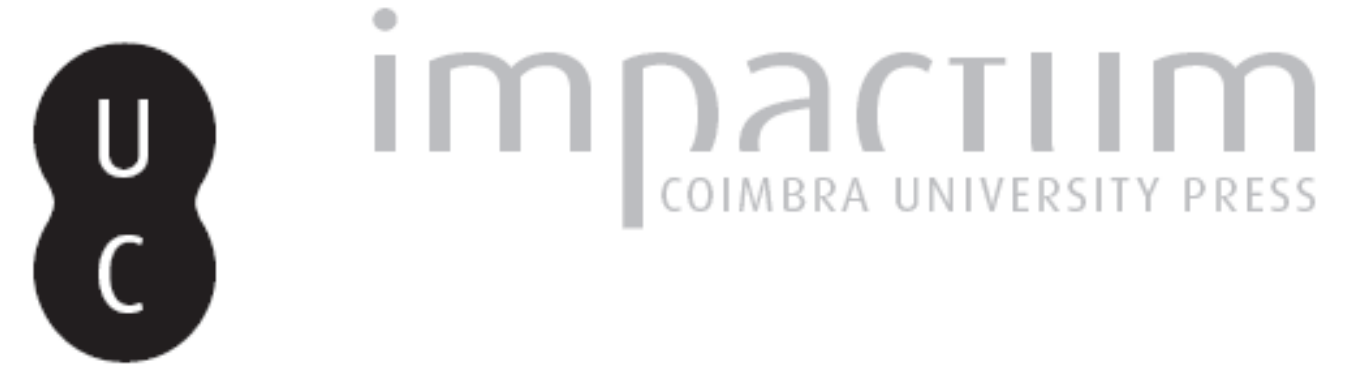

Lucêncio, Bispo de Conimbriga, e as origens do mosteiro de Lorvão

Autor(es): $\quad$ Borges, Nelson Correia

Publicado por: Imprensa da Universidade de Coimbra

URL persistente:

URI:http://hdl.handle.net/10316.2/45680

DOI:

DOI:https://dx.doi.org/10.14195/1647-8657_23_10

Accessed : $\quad$ 26-Apr-2023 09:33:20

A navegação consulta e descarregamento dos títulos inseridos nas Bibliotecas Digitais UC Digitalis, UC Pombalina e UC Impactum, pressupõem a aceitação plena e sem reservas dos Termos e Condições de Uso destas Bibliotecas Digitais, disponíveis em https://digitalis.uc.pt/pt-pt/termos.

Conforme exposto nos referidos Termos e Condições de Uso, o descarregamento de títulos de acesso restrito requer uma licença válida de autorização devendo o utilizador aceder ao(s) documento(s) a partir de um endereço de IP da instituição detentora da supramencionada licença.

Ao utilizador é apenas permitido o descarregamento para uso pessoal, pelo que o emprego do(s) título(s) descarregado(s) para outro fim, designadamente comercial, carece de autorização do respetivo autor ou editor da obra.

Na medida em que todas as obras da UC Digitalis se encontram protegidas pelo Código do Direito de Autor e Direitos Conexos e demais legislação aplicável, toda a cópia, parcial ou total, deste documento, nos casos em que é legalmente admitida, deverá conter ou fazer-se acompanhar por este aviso.

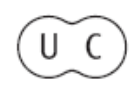


FACULDADE DE LETRAS

INSTITUTO DE ARQUEOLOGIA

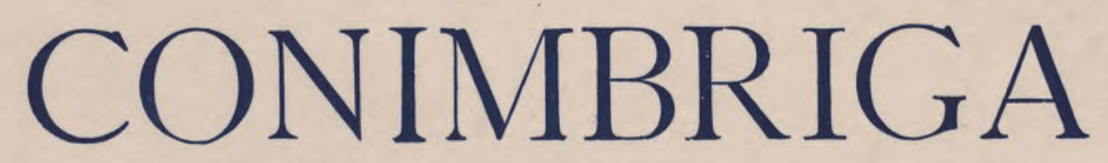

VOLUMEXXIII

UNIVERSIDADE DE COIMBRA

1984 
NeLSON CORREIA BORgES

Assistente da Faculdade de Letras de Coimbra

LUCÊNCIO, BISPO DE CONIMBRIGA, E AS ORIGENS DO MOSTEIRO DE LORVÃO

Conimbriga, XXIII (1984), p. 143-158

RESU Mo: Uma pedra lavrada com ornato visigótico, do século vi, recentemente encontrada no Mosteiro de Lorvão, vem permitir fazer a revisão do problema das origens deste cenobio. Este achado confirma a existência em Lorvão de um ermitério de certa importância naquela época e a verosimilhança da literatura monástica a tal respeito, tida até agora por fantasiosa, dada a falta de documentos escritos fidedignos. Permite igualmente que surja com maior nitidez a figura de Lucéncio, fundador da instituição e único bispo de Conimbriga conhecido.

RÉSUmé : L'étude d'une pierre ornée de décors wisighotiques du vième siècle, récemment trouvée au Monastère de Lorvão, nous permet de réexaminer le problème des origines de ce couvent. Cette découverte vient prouver l'existence, à Lorvão, d'un ermitage important à l'époque et, en même temps, la vraisemblance de ce que la littérature monastique nous disait à ce propos. En effet, on l'a toujours considérée fantaisiste car on n'avait pas des documents écrits dignes de foi. Cette découverte fait également ressortir plus nettement l'image de Lucentius, le fondateur de l'institution et le seul évêque connu de Conimbriga. 
(Página deixada propositadamente em branco) 


\section{LUCÊNCIO, BISPO DE CONÍMBRIGA, E AS ORIGENS DO MOSTEIRO DE LORVÃO}

Nunca foi posta em dúvida a existência histórica de Lucêncio, o primeiro bispo de Conímbriga de que há notícia certa. O que surgiu como objecto de suspeita ou rejeição é o papel que normalmente lhe tem sido atribuído de fundador do Mosteiro de Lorvão.

Com efeito, sabe-se de Lucêncio que assistiu aos dois primeiros concílios de Braga, em 561 e 572, tendo firmado as respectivas actas na qualidade de bispo de Conímbriga, cidade certamente detentora de uma das mais antigas sés episcopais de Portugal, sobre cujas origens e primeiros bispos correm escritas algumas lendas $(\mathrm{x})$, não havendo todavia dados fidedignos mais antigos que os já referidos. Aliás, é escassíssima a quantidade de factos conhecidos e documentos escritos merecedores de crédito respeitantes não só aos bispados portugueses desta época mas a todo o período em geral, pelo que caberá à arqueologia dar um importante contributo para o melhor conhecimento de tão recuadas e obscuras eras.

Do venerável Lucêncio falam quase todos os cronistas monásticos espanhóis e portugueses $\left({ }^{2}\right)$, referindo que $\mathrm{S}$. Bento teria enviado doze monges para a Península Ibérica, dos quais alguns,

(x) Das origens da diocese, em sequência às pregações de Sant'Iago e de Santo Anastácio, mártir, seu primeiro bispo, fala, por exemplo, GEORGE Cardoso, no seu Agiologio Lusitano dos Sanctos e Varoens illus*res em virtudes, I, Lisboa, 1652, p. 18.

(2) Ver a bibliografia em Francisco Leitão Ferreira, Catalogo Chronologico-Critico dos Bispos de Coimbra, incluído na Collecçam dos Documentos e Memorias da Academia Real da Historia Portugucza, IV, Lisboa, 1724, p. 7-9. 
chefiados por Lucêncio, passaram à Lusitânia e, chegados ao território conimbricense, então senhoreado pelos suevos, foram fixar sede em Lorvão. Lucêncio, pelas suas qualidades e cultura, foi o primeiro abade da jovem comunidade, acabando mais tarde por ser eleito para presidir à catedral de Conímbriga. Faleceu em 10 de Abril de $580\left(^{3}\right)$. O famigerado Fr. Bernardo de Brito ( $\left.{ }^{4}\right)$ deu a conhecer o seu assento de óbito, exarado em «hum livro de obitos muy antigo da propria casa» (Lorvão), onde se afirmava: Eadem die obijt venerabilis Lucentius primus quondam Abbas Laurbani, postea vero ad episcopatu Colimbrigensis civitatis assumptus, qui literis, et virtutibus clarus multis inter fuit Concilijs, plurimunque juvit conversionem haereticorum, et praedicationem veri dogmatis $\left(^{5}\right)$.

$\mathrm{O}$ pequeno texto é uma importante súmula de elementos a respeito de Lucêncio, onde se realça o seu papel de evangelizador, razão por que os cronistas de seiscentos o colocam a par de

S. Martinho de Dume, dando a ambos o título de «Apóstolos dos Suevos». Contudo, o facto de ele nos ser apresentado por um historiador apologético como Fr. Bernardo de Brito, extraído de um (hoje) ignorado obituário é motivo para que tenha sido encarado com alguma reserva. O seu conteúdo, porém, nada tem de extraordinário. A acção apostólica de Lucêncio, entendida mais como evangelização dos povos do que combate ao arianismo, como queriam os cronistas monásticos, numa época em que o conhecimento do cristianismo devia ser ainda muito fraco, sobretudo a nível do homem do campo, seria uma das actividades mais lógicas para um monge missionário. Igualmente o seu conhecimento das letras não pode ter deixado de pesar na ascensão à mitra episcopal. Quanto à presença do bispo de Conímbriga

(3) De Lucêncio tratam com algum pormenor GEORGE CARDoso, Agiologio Lusitano, II, Lisboa, 1657, p. 496 e 504-505, e Fr. Lẽ̃o de S. Tomás, Benedictina Lusitana, I, Coimbra, 1644, p. 306-307.

$\left(^{4}\right)$ Segunda Parte da Monarchia Lusytana, Livro Sexto, Capítulo XII,

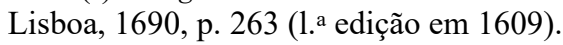

$\left.{ }^{5}\right)$ No mesmo dia (10 de Abril) morreu o venerável Lucêncio, que foi um tempo primeiro abade de Lorvão e depois sublimado no bispado da cidade de Coimbra, o qual resplandeceu com letras e virtudes, se achou presente a muitos concílios e ajudou muito à conversão dos herejes e à pregação da verdadeiia fé. - Tradução de FR. BERNARDo DE BRITo, ibidem. 
nos concílios bracarenses, o primeiro reunido sob Teodomiro e presidido pelo metropolita Lucrécio, seria de estranhar que ela não se tivesse verificado.

Lucêncio surge assim indissoluvelmente ligado às origens do Mosteiro de Lorvão, problema que tem sido objecto de viva controvérsia desde há séculos e que importa rever.

Alguns autores remontam a sua fundação a meados do século $\mathrm{v}$, nomeadamente por Paulo Orósio, tese facilmente rebatível $\left(^{6}\right)$ e em que não nos deteremos.

Foi igualmente Fr. Bernardo de Brito $\left({ }^{7}\right)$ quem deu à estampa urna nota manuscrita num dos códices que ele afirma ter visto na livraria de Lorvão, «memoria antiga, escrita no fim de hum liuro de mão da propria casa, que conthem as palauras seguintes, trasladadas fielmente»:

Domus nostra Lurbani constructa fuit viuète patre nostro Benedicto, et dedicata sanctis Martyribus Mameti et Pelagio, illi enim qui venerunt deferebant reliquias istorü, propter quod assumpserunt illos in patronos, et fuit dedicata et ecclesia, illis quarto Kal. lunij (s).

A ser verdade o que se contém nesta nota, facilmente se constata que o inicio da vida monástica em Lorvão ocorreria entre as datas de $537 \mathrm{em}$ que os cronistas situam a vinda dos primeiros beneditinos para a Hispánia, e 547, ano provável da morte de S. Bento. Fr. Bernardo de Brito e Fr. Leão de S. Tomás partiam do pressuposto que os primeiros monges laurbanenses eram beneditinos, o que é muito difícil de aceitar. De facto, sabe-se hoje que a Regra que S. Bento escreveu para Monte Cassino só se começou a divulgar depois que os Lombardos destruiram o mosteiro e a comunidade se refugiou em Roma, em 580. A missio- *s.

${ }^{6}$ ) A propósito veja-se o que escreve Fr. LẼ̃o de S. Tomás, ob. cit., p. $308-314$.

$\left(^{7}\right)$ Primeyra Parte da Chronica de Cister, Livro Sexto, Cap. XXIX, Lisboa, 1602, p. 447.

$\left(^{8}\right)$ «A nossa casa de Lorvão foi fundada em vida de nosso padre

S. Bento e dedicada aos santos Mártires Mamede e Pelágio, porque aqueles que a vieram fundar traziam reliquias destes santos, e por isto os tomaram por padroeiros, e foi dedicada a igreja em louvor deles aos 20 de Maio». - Tradução de Fr. Bernardo de Brito, ibidem. Houve porém lapso na data, urna vez que quarto kal. lunij corresponde a 29 de Maio. 
nação dos beneditinos na Europa só se inicia com o pontificado de Gregorio Magno (590-604) e a íntegra adopção da Regra na Península Ibérica não se verificou antes do séc. x, ou, melhor, antes do concílio de Coiança, de $1050{ }^{(9)}$. Até aí os mosteiros do Ocidente seguiam um sistema eclético designado por Regula mixta $\left({ }^{10}\right)$, geralmente estabelecido pelos próprios abades, baseado embora nas virtudes da obediencia, pobreza e castidade, consagradas pela Regra de S. Bento $\left({ }^{n}\right)$.

Tal foi certamente o caso de Lorvão, onde a Regra de S. Bento só deveria ter sido adoptada em definitivo por 1064, aquando da reconquista de Coimbra por Fernando Magno, ou pouco antes, e para onde se tem igualmente aventado a hipótese de ter sido no início um mosteiro dobrado ( ${ }^{12}$ ), isto é, uma dúplice comunidade masculina e feminina, com edifícios separados mas com igreja e prelado comuns.

Que os primeiros monges de Lorvão não eram beneditinos, é um dado implícito nas próprias memórias do mosteiro. Assim, durante as obras de reforma dos edifícios que se operaram nos séculos xvi e xvn foram postas a descoberto algumas sepulturas dé monges e abades $\left({ }^{13}\right)$, entre as quais a de um corpo inteiro com hábito negro cingido por uma correia ${ }^{(14)}$. Ora tal adorno é característico dos agostinianos, pelo que é de presumir que em

(9) Cf. José Matтoso, art. Beneditinos, em Verbo-Enciclopédia Luso-Brasileira de Cultu? a, III, Lisboa, 1965, col. 1051.

(10) Gabriel de Sousa, art. Beneditinos, em Dicionário de História da Igreja em Portugal, II, Lisboa, 1981, p. 340-407.

(u) E igualmente pelas regras de Santo Isidoro e de S. Frutuoso. A este respeito e sobre as comunidades religiosas do período suévico-visigótico veja-se Fortunato de Almeida, História da Igreja em Portugal. I, Porto, 1967, p. 51-56, e também Fr. Justo Pérez de Urbel, El Monasterio en la oida española de la Edad Media, Barcelona, 1942.

(12) T. Lino D’AssumpÇão, As Fniras de Lorvão, Coimbra, 1899, p. $35-49$.

(13) Arquivo Nacional da Toire do Tombo, Mosteiro de- Lorvão, Livi o das Preladas (Códice N. ${ }^{\circ}$ 309), foi. 5v.. Fr. Leão de S. Tomás, ob. cii., p. 315-316.

(14) Miguel Joachino de Freytas, Novas Notas da Analysis Benedictina Descubertas pelo Be verendissimo P. M. Fr. Francisco de Santa Maria..., Madrid, 1734, p. 99. 
certo momento da vida monástica em Lorvão ali houvesse eremitas de Santo Agostinho (15).

Outra pista a seguir, no que toca à nota sobre a fundação da casa laurbanense, é a que diz respeito aos seus patronos, os mártires Mamede e Pelágio, abundantemente citados na documentação dos séculos x a xn.

S. Mamede teria sido martirizado em Cesareia da Capadócia, em 275. O seu culto em breve se difundiu pelo Oriente, alcançando mais tarde o Ocidente: as relíquias teriam sido trasladadas para Jerusalém, depois para Constantinopla e finalmente (em várias fases) para Langres, na França, cuja catedral é dedicada ao santo. Em Portugal o seu culto generalizou-se de forma notável, provavelmente a partir de Lorvão, sendo ainda hoje o santo patrono de 65 paróquias $\left({ }^{16}\right)$.

Quanto a S. Pelágio, Pelaio ou Paio, póe-se o problema de saber qual dos santos com este nome seria o patrono de Lorvão. Um Pelágio do século iv, bispo de Laodiceia, na Siria, incluido no martirologio romano a 25 de Março, está fora de causa, por não ser mártir e por o seu culto ter sido demasiado restrito. Restam o S. Pelágio, padroeiro de Constança (Alemanha), de que há carencia de dados históricos — teria sido martirizado em Aemona, na ístria, cerca de 283, mas as suas reliquias só em 904 seguiram para Constança $\left({ }^{17}\right)$; tem a festa a 28 de Agosto - e o homónio mártir de Córdova, supliciado em 925 com 13 anos de idade, que parece ter nascido na região de Coimbra, e cujas relíquias foram enviadas

(15) Vários argumentos neste sentido são aduzidos na obra citada na nota precedente (p. 87-99) que já é um segundo comentário polémico ao livro de Fr. Manoel dos Santos, Analysis Benedictina, em que este pretende provar que a ordem de S. Bento é a mais antiga em Portugal, na sequência da famosa questão havida entre Jerónimos e Beneditinos sobre a precedência de lugar em actos públicos.

(16) J. C. Freita S Barros, Vida de. São-Mamede Mártir, Lisboa, 1942. p. 35-39. A distribuição geográfica das freguesias sob a invocação de São Mamede parecer apontar para a difusão do seu culto durante a alta Idade Média, a partir de Lorvão. Com efeito, elas situam-se, na quase totalidade, a norte da diocese de Leiria, apenas ficando para sul, Ventosa (Torres Vedras) e Lisboa. A sul do Tejo há apenas uma paróquia, em Évora.

(17) Enciclopédia de la Religión Católica, V, Barcelona, 1953, col. 1447. 
para Leão em 967, sendo, em 985, trasladadas para Oviedo; tem a festa a 26 de Junho.

O Prof. Pierre David, num estudo sagaz e oportuno $\left({ }^{18}\right)$, procurou demonstrar que o S. Pelágio venerado em Lorvão era o mártir de Córdova, pelo que a sua adopção como patrono não se poderia ter dado antes de meados do século $\mathrm{x}$ e todos os documentos anteriores que o referissem não poderiam deixar de ser falsos, mal datados, ou com palavras intercaladas. A primeira dificuldade que se levanta a esta asserção resulta da existêndia de vários documentos do Livro Preto da Sé de Coimbra e do Livro dos Testamentos de Lorvão, anteriores a 950, que o citam. Um desses documentos é a insuspeita doação da condessa D. Oneca, mãe de Ximeno Dias e de Mumadona, datada de 928. Ora não é crível que três anos após o martírio do jovem Pelágio em Córdova, este já fosse venerado em Lorvão. $O$ facto de o seu nome não aparecer em alguns documentos anteriores também não é de ter em conta, uma vez que S. Pelágio era um patrono secundário, verificando-se que, mesmo em épocas tão posteriores quanto o século xn, a maior parte da documentação refere apenas S. Mamede $\left({ }^{19}\right)$.

Outro argumento que nos parece de considerar é o conhecimento que havia no mosteiro, por tradição, de que o seu patrono era o de Constança e não o de Córdova. Bernardo de Brito $\left({ }^{20}\right)$, querendo provar que o mártir cordoves era natural de Coimbra transcreve de um cerimonial antigo de Lorvão o seguinte: $\mathrm{V}$. kal. Septembr. celebramus festum Sancti Pelagij Martyris cu luminibus triplicatis, majestatibus, et coronis; non illius, qui ex hac patria natus Cordubae pugnavit pro fide Christi. XV. kal. Iulij. ponitur enim tunc simplex lumen, et non coronatur altare (21). Abstraindo do

(18) Les Saints Patrons d'églises entre Minho et Mondego jusqidà la fin du XIe siècle, «Revista Portuguesa de História», II, Coimbra, 1943, p. 221-254.

(19) Examinando a documentação do século XII transcrita por FERNANDo Garcia Pires, O Mosteiro de Lorvão. Subsídios para a sua História - 1126 a 1181, Coimbra, 1971 (policopiado), verifica-se que dos 31 diplomas que invocam os patronos de Lorvão, apenas 11 referem S. Pelágio.

${ }^{(20)}$ Segunda Parte da Monarchia Lusytana, Livro Sétimo, Cap. XIX, Lisboa, 1690, p. 473.

(21) Brito faz a seguinte tradução: «Acs vinte e oito de Agosto se celebra nesta casa a festa de São Pelayo Martyr com seis velas no altar, \& cõ as reliquias, ou imagens, \& coroas que se devião tirar em publico 
problema da autenticidade deste texto, o que não se pode negar é que ainda nos finais do século xvi Lorvão não confundia o seu patrono com o santo peninsular. Aliás, o $\mathrm{S}$. Pelágio de Lorvão tem uma iconografia muito semelhante à de S. Sebastião, bastante diferente das características e atributos do santo de Córdova, e é curioso notar que, em 1623, quando o pintor Miguel de Paiva, que a abadessa D. Margarida da Silveira mandara vir de Lisboa, executou para o mosteiro, entre outras, uma grande tábua com S. Pelágio e S. Mamede, teve de seguir as instruções da abadessa, no que tocava ao tema dessa pintura (22).

O Dr. Rui de Azevedo publicou em 1933 um notabilíssimo estudo baseado nos mais antigos documentos escritos fidedignos de Lorvão (23), contidos no Livro dos Testamentos, em que, após profunda análise e reflexão conclui «que o mosteiro de Lorvão, em vez de esmorecida reminiscência cristã, a que as hostes do conde Ermenegildo (24) vieram insuflar nova vida, se manifesta como instituição moça e activa, fundada pelo elemento neo-cristão que desceu às margens do Mondego na vanguarda da reconquista. Reputo-o, por conseguinte, fundação do último quartel do século ix, um pouco posterior à tomada de Coimbra no ano de 878.» (25).

Esta fundamentada opinião não podia deixar de fazer considerar falsas as notas transcritas por Fr. Bernardo de Brito, quando não mesmo uma invenção do cronista alcobacense. De um momento para o outro passaram a ser tidos como pura fantasia todos os relatos, listas de abades, relações com mouros, etc., respeitantes à vida do mosteiro em datas anteriores a 878 .

nas festas solenes; \& não he este o Santo natural desta terra, que morreo na Cidade de Cordova pela fè de Jesu Christo, aos 26. de Junho; porque então não se poem, mais que o lume ordinario, nem se orna o altar com coroas.»

(22) George Cardoso, no seu Agiologio Lusitano, III, Lisboa, 1666, p. 443, 449, 829-831 e 837-839 distingue igualmente o patrono do Monteiro de Lorvão do S. Pelágio martirizado em 925.

(23) O mosteiro de Lorvão na reconquista cristã, «Arquivo Histórico de Portugal», I, Lisboa, 1933, p. 183-239.

(24) Chefe militar da reconquista de Coimbra de 878 , ao sei viço de Afonso III de Leão - a nota é nossa.

(25) Art. cit., p. 201. 
Pela nossa parte, presentemente, pensamos que Brito transcreveu fielmente algumas notas cheias de interesse que encontrou em códices de Lorvão. A que respeita à fundação da casa laurbanense é, evidentemente, um registo tardio, anterior ao século xm, que reflecte a tradição corrente. Não é difícil, aliás, encontrar noutros livros de Lorvão anteriores a Brito afirmações semelhantes. É o caso do Livro de Reportório, feito em 1543 por ordem da abadessa D. Ana Coutinho, e que não é mais que um índice de documentos, onde se afirma, a foi. 45: ... «parece que no / ano do senhor quatrocentos e tantos antes de mil / jaa Loruuão era de religiosos e casa de ora / çam e peramaneceo sempre asy ainda que depões / os mouros tomarasem a Espanha [...]» (26). Também no Livro das Preladas (27), feito em 1605, a foi. 4, há uma Lembrança dos Abb. ${ }^{e s}$ de São Bento q neste Most. ${ }^{r o}$ de / Lorvão ouve sendo de frades e se achavão escritos por letra / da m.e D. Izabel de Mello q. serviu de Carturaria quarenta / Annos, que principia: $« \mathrm{O} \mathrm{p}^{\text {ro }}$ Padre e fundador foi Lucêncio e dipois Bispo de Coimbra» $\left({ }^{28}\right)$.

Porém, no que toca à antiguidade do mosteiro, outras fontes que não os documentos escritos devem ser trazidas à colação.

Já em 1977 tivemos o ensejo de salientar a importância de que se revestiam certos elementos fornecidos pela arqueologia, testemunhando a existência de populações em Lorvão em épocas anteriores ao século vi ${ }^{(29)}$, sobretudo no período romano. Justamente deste período são um fuste de coluna de mármore branco,

(26) Arquivo Nacional da Torre do Tombo, Mosteiro de Lorvão, Códice N. ${ }^{\circ}$ 326. Rui de Azevedo, art. cit., p. 211, transcreve igualmente esta referência que vem inserta no sumáiio e comentário a uma doação de Serpins.

(27) Arquivo Nacional da Torre do Tombo, Mosteiro dc Ltrvão, códice N. ${ }^{\circ} 309$.

(28) Escolhemos este exemplo por se referir a Lucêncio. A madre escrivã anota no fim da lista, que aliás tem bastantes lacunas, que poderia aver mais abb.es mas dis a dita m.e / D. ${ }^{a}$ lzabd de Mello q. destes da fe p.los aver Udos no Cartorio, o que vem em abono das notas que Fr. Bernardo de Brito recolheu e publicou.

(29) O Mosteiro de Lorvão, Coimbra, 1977, p. 5-6. Correia Borges, Um machado de pedra polida em Lorvão, «Notícias de Penacova», 1989, Penacova, 29.09.1973, p. 2. 
observado pelo Doutor A. Nogueira Gonçalves, e uma ara ${ }^{(30)}$. Dado de excepcional importância, porém, é a inscrição romana, encontrada por volta de 1914, numa das paredes do mosteiro, durante umas obras ${ }^{(31)}$. Seguiu para o Museu Nacional de Arqueologia, onde tem permanecido ignorada de quantos se têm debruçada sobre a história de Lorvão. É um excelente exemplar que recorda a memória de Gaio Valério Juliano Seiliense, mandado lavrar por seu irmão Marco António Juliano, que sem hesitação se pode datar de princípios ou meados do século i.

O que seria Lorvão na época luso-romana? Certamente uma villa onde se instalou a família referida na inscrição e que mais tarde veio a acolher igualmente os primeiros monges.

A origem latina do fito-topónimo Lorvão aponta igualmente para isso. Segundo a tradição, «se tomou de hum Loureiro antigo que no dito lugar estava plantado» $\left({ }^{32}\right)$, loureiro que de tão antigo

(30) Vergilio Correia e A. Nogueira gonçalves, Inventário Artístico de Portugal. Distrito de Coimbra, Lisboa, 1952, p. 194.

(31) Leite de VASconcelos, Inscrição romana de Lorvão, «O Archeologo Português», 19, Lisboa, 1914, p . 365-366. Correia Borges A Inscrição Romana de Lorvão, «Notícias de Penacova», 2126, Penacova, 02.09.1977.

(32) Fr. Lẽ̃o de S. Tomás, Benedictina Lusitana, I, Coimbra, 1644, p. 306. Ao mesmo se referem igualmente outros autores seiscentistas. Sem esquecer a artificiosa divisão da palavra Lorvão por dois versos, feita pelo poeta da écloga Crisfal, lembraremos um curioso poema do século xvm intitulado: Laureolas cristalinas. Poema htroico-sacro. Formado das prodigiosas vidas das mdhores Sereyas do Mondego as Serenissimas e Augustissimas Raynhas S. Thereza e S. Sancha [...]. Por Quiteria Rosa Ferreira Themudo de Laserra e Salema, onde se diz, a certo passo do Canto VI:

«Aqui ha tradição, fama constante de que um bello loureiro se elevava e entre as agoas nascido, era brilhante»...

e mais adiante:

«De estructura soberba, em solidão,

fabricaram os monjes seu convento, e aqui, entre aurea acclamação, viveram venerados, com augmento; 'té que chegando o da relaxação Thereza o reformou, e foi portento; mas estes, por o louro que a agoa apura aqui dão a Lorvão nomenclatura.»

Veja-se T. Lino D'AssumpÇão, As Freirás de Lorvão, Coimbra, 1899, p. 173-177. 
era já carcomido e oco (vão), donde a origem do nome. Trata-se, como é evidente, de uma etimologia popular, ainda não há muitos anos contada em Lorvão nos serões de Inverno, à lareira, ou, durante $\mathrm{o}$ Verão, nas rodas das paliteiras. Porém, apesar dos argumentos recentemente aduzidos por Joseph M. Piel ( $\left.{ }^{33}\right)$, para demonstrar que o topónimo deve ser originário de «(Villa) Norbani», do senhorio da época latina, continuamos a preferir a raiz , $i$. dada a abundância de loureiros que ainda hoje, e apesar de tudo, crescem em grande número e quase espontaneamente por todo o vale de Lorvão, e que no passado, juntamente com os castanheiros, povoavam todas as vertentes da serra, havendo mesmo na microtoponímia outros exemplos a apontar.

Outro dado importante, que atesta a existência de uma comunidade cristã em Lorvão, é proporcionado pelo Parochiale suevo, datável de entre 572 e 582 (34). Nesta lista de paróquias, entre as sete que compõem a diocese conimbricense, figura em quarto lugar a de Lurbine que, bem ou mal grafado, não pode deixar de corresponder ao moderno Lorvão ${ }^{36}$ ), onde havia alguns anos se teriam instalado os primeiros monges e erguido a basilica dos santos mártires cujas relíquias os haviam acompanhado na jornada. O santuário em breve alcançaria a importância suficiente para se transformar em sede de paróquia. Não se deve esquecer que em Lorvão a igreja do mosteiro funcionou como paroquial até 1640 ano em que, devido às contendas surgidas com o bispo D. João Mendes de Távora, por este querer ter jurisdição no

(33) Sobre a origem do nome do mosteiro de LORVÃO, «Biblos», 57, Coimbra. 1981, p. 167-170.

(34) A este respeito veja-se o já clássico estudo de Pierre David, incluído em Études Historiques sur la Galice et le Portugal du VIe au XIIe siècle, Paris-Lisboa, 1947, p. 1-82.

(35) «Sur Lurbine je n'ai pas d'hypothése à présenter», escreveu PIERRE DAvid (ob. cit., p. 78). Na verdade a identificação de Lurbine com Lorvão punha alguns problemas, face ao que este autor já havia anteriormente exposto acerca dos santos patronos. Mais recentemente, o Prof. Avelino de Jesus da Costa, num artigo para a Enciclopédia Verbo (Vol. 15, Lisboa, 1973, col. 739-748), incluiu um mapa de Portugal paleocristão, em que situa Lurbine no local do mosteiro de que vimos tratando. 
mosteiro, sob o pretexto de que a igreja era paroquial, as freirás de Lorvão obtiveram, a 7 de Novembro, dois breves do papa Urbano VIII para poderem extinguir a paróquia e fundá-la de novo com sede na ermida de Nossa Senhora da Esperança, fora do recinto monástico.

Não há muito tempo tivemos a alegria de descobrir em Lorvão um testemunho da maior importância para o esclarecimento do problema das origens do seu mosteiro.

Trata-se de uma pedra lavrada, de mármore cinzento escuro com veios esverdeados, proveniente, com toda a probabilidade, das pedreiras das proximidades de Sazes de Lorvão, nas faldas do Buçaco ( $\left.{ }^{36}\right)$. Encontra-se incrustada na face sul da torre sineira do mosteiro, servindo como friso a uma das cornijas - a mais baixa da torre. Esta circunstância, conjugada com a altura a que se encontra e o revestimento da argamassa que parcialmente a encobria, fizeram com que até hoje passasse completamente despercebida.

Esta torre campanário apresenta duas épocas distintas de construção: uma primeira iniciada em 1597, a partir da qual se fez o acrescento da segunda metade do século xvm. A pedra encontra-se colocada no cimo do envasamento onde assentava o corpo da torre quinhentista com as ventanas e seu remate hemisférico.

A época de 1597 foi de grandes remodelações: «se abrirão no Cemiterio os alicerçes da torre dos sinos, \& se lançou por terra hü campanario velho» $\left({ }^{37}\right)$, além do achamento das sepulturas já referido. A pedra foi indubitavelmente aqui colocada nesta época, proveniente, talvez, do campanário velho, do claustro, da igreja, ou de qualquer outro local ignorado, que já não era o de origem.

(36) Ver a estampa incluída neste trabalho. O desenho é da autoria da artista Clara Portas, a quem manifestamos a nossa maior gratidão pela colaboração prestada.

(37) Conforme testemunho da madre D. Margarida de Vasconcelos, transcrito por Fr. Leão de S. Tomás, na Benedictina Lusitana, I, Lisboa, 1644 , p. 315-316. 
É um espécime notável, com $0,94 \mathrm{~m}$ de comprimento por $0,14 \mathrm{~m}$ de largura, encontrando-se fragmentado nas duas extremidades, pelo que se ignora quais seriam as dimensões originais. Apenas está visível uma face, não sendo possível verificar se teria mais alguma trabalhada e assim detectar qual a sua função arquitectónica primitiva.

Apresenta um dos motivos típicos da arte visigótica: a silva ou haste ondulante com cachos de uvas e gavinhas dentro da curva, já conhecida desde a mais remota antiguidade ( $\left.{ }^{38}\right)$, mas utilizada pela arte paleocristã como símbolo de Cristo, do Seu sangue, feito vinho eucarístico, e da própria Igreja (39). No exemplar de Lorvão há apenas cachos de uvas que, ao contrário do que é habitual, não têm contorno exterior, são simples agrupamentos cordiformes de bagos. Os cachos são separados por gavinhas, em grupos de três, isto é, de três em três cachos não existe a gavinha. A haste ondulante é contida entre duas cordas laterais molduradas por filetes. Não se conhecia até agora exemplar semelhante a não ser $\mathrm{o}$ fragmento de Eira Pedrinha (no Museu Machado de Castro, de Coimbra), aliás de diminutas dimensões.

A pedra encontra-se muito patinada e com algum desgaste. Ainda assim, o relevo chega a ultrapassar um centímetro em alguns pontos. O nível de execução deste monumento, com composição muito cuidada e a escultura a evidenciar perícia e apuramento, permitem-nos, sem hesitação, datá-lo do século vi.

Outros testemunhos poderão ainda surgir em Lorvão, em ordem a clarificar este problema, bastando que para tanto se façam sondagens e escavações, embora nesta época as construções fossem muito modestas; por vezes não passavam de choças onde os monges viviam isolados, ou de pequenas salas em que os cinco ou seis cenobitas iniciais dormiam ou tomavam as suas refeições. A igreja, porém, a avaliar pela pedra que lhe pertenceria, devia ser um edifício de bom nível de que poderão ser encontrados

(38) J. Puig I CADAFAlCh, VArt Wisigothique et ses survivances, Paris, 1961, p. 60.

(39) Fernando António de Almeida e Silva Saldanha, Arte Visigótica em Portugal, Lisboa, 1962, p. 88. 
outros vestígios. Para já e face ao exposto, parece-nos que os dados referidos por Fr. Bernardo de Brito acerca da antiguidade da vida monástica em Lorvão não são de recusar, mas antes de admitir como urna tese válida.

Lucêncio é um nome latino. Esta personalidade bem poderia ter vindo da Itália com os seus companheiros — não veio de lá também, na mesma época, S. Martinho de Dume? Bem poderiam ser portadores das relíquias de Mamede e Pelágio, chegadas à Itália do Oriente e da Istria, e vir assentar arraiais na villa romana, decadente e quiçá abandonada de Lorvão, onde estabeleceram a sua base contemplativa, de trabalho, e sobretudo de missionação.

Que razões os poderiam ter levado a escolher este local ? A primeira é constituída pela amenidade do sítio, abundante de boas águas fertilizadoras, com campos de cultivo marginais à ribeira e bons terrenos pelos inúmeros vales que sulcam a serra. A instabilidade dos tempos exigia que perto houvesse refúgio para quando fosse necessário e esse tinham-no com facilidade os primeiros monges nas encostas da serra, nos montes, nos meandros dos vales e valeiros, cobertos de denso arvoredo e matagais, cujos segredos eles foram pouco a pouco desvendando. Lorvão tinha a vantagem do seu isolamento, de ser um local oculto a que se chegava não sem alguma dificuldade, mas ao mesmo tempo suficientemente perto da florescente Emínio, apenas a escassas duas léguas e meia, e do castelo roqueiro de Penacova, que não chegava a distar uma légua; perto igualmente da grande via de penetração no interior que era o rio Mondego.

$\mathrm{O}$ que se passou depois em Lorvão até à invasão dos muçulmanos e à reconquista de 878 é outra parte da historia que só se poderá igualmente rever com o contributo da arqueologia.

Lucêncio já não seria propriamente um jovem quando foi ocupar a cátedra episcopal de Conímbriga e sendo ele o primeiro bispo de Conímbriga conhecido, será também simultaneamente o último. Terá sido Lucêncio quem mudou a sede do bispado para Emínio, trazendo consigo o nome que acabaria por prevalecer sobre o da velha cidade das margens do Munda? É hipótese que julgamos de considerar. De concreto apenas sabemos que o seu sucessor assinou as actas do concílio de Toledo de 589 como 
Possidónio eminiense, o que nos leva a supor que nesta data a residência dos bispos já era Emínio $\left({ }^{40}\right)$.

A acreditar no assento de óbito referido, Lucêncio faleceu a 10 de Abril de 580, já de avançada idade, tendo provavelmente resignado ao cargo que ocupava e regressado a Lorvão, onde terminaria os seus dias.

(40) Opinião, aliás, já expressa por Jorge de Ala RCÃo, Portugal Romano, Lisboa, 1973, p. 182. O facto de Possidónio assinar como eminiense fez equivocar António de Vasconcelos que julgou tratar-se de um outro bispado «encravado na diocese de Coimbra» (Lista Cronológica des Bispos de Coimbra, Coimbra, 1924, p. 10).

Conimbriga, 23 (1984), 143-158 


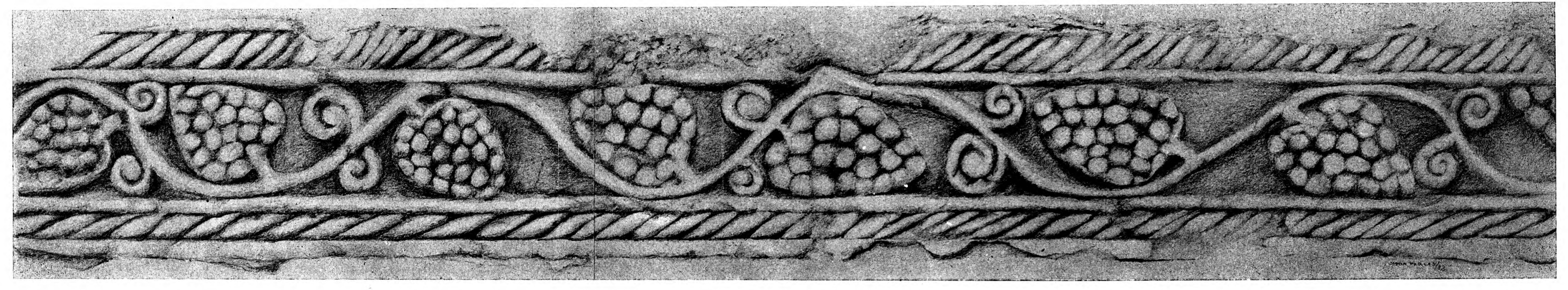


(Página deixada propositadamente em branco) 


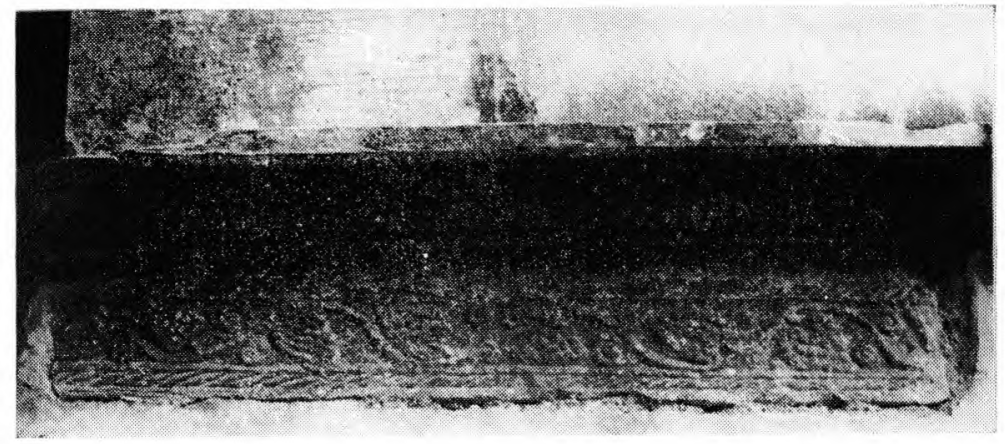

Pedra visigótica colocada sob uma das cornijas da torre sineira do Mosteiro de Lorvão

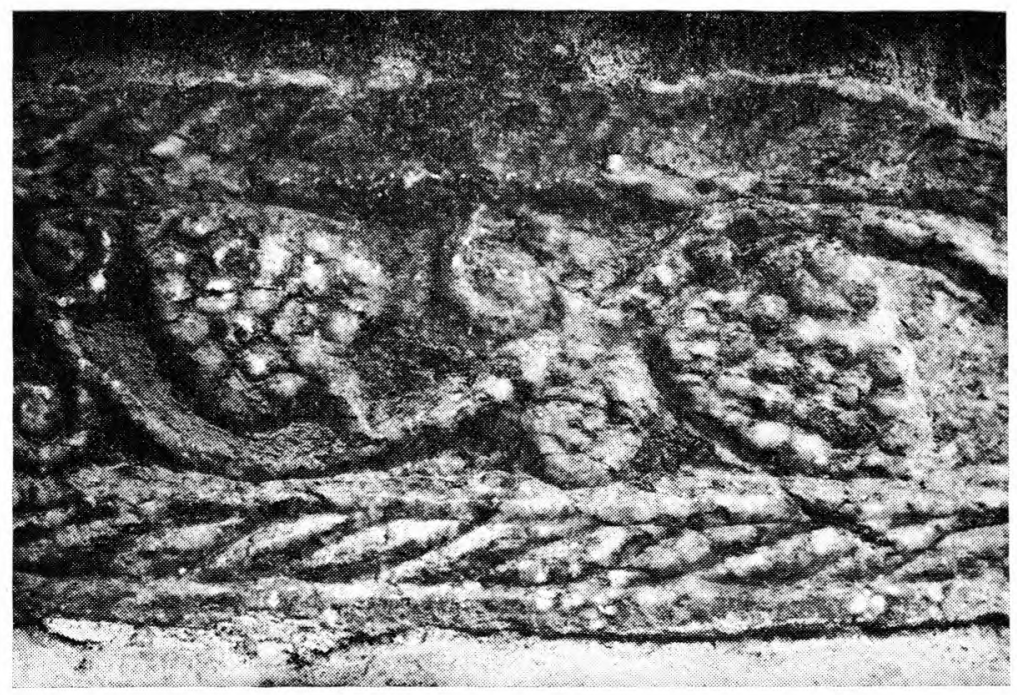

Pormenor da decoração 